\title{
Calculation of periodic roof weighting interval in longwall mining using finite element method
}

\author{
Navid Hosseini ${ }^{1}$, Kamran Goshtasbi ${ }^{2}$, Behdeen Oraee-Mirzamani ${ }^{3}$
}

\begin{abstract}
The state of periodic loading and the interval of periodic roof weighting have an important role in geomechanical stability, and hence in the continuity of longwall mining operations. In this paper, the mechanism of roof caving in longwall mining - together with the effect of engineering and geomechanical properties of surrounding rock masses on the magnitude and timing of periodic loading - is studied. For this purpose, a longwall mine is first modeled using Phase2 software, and then, by simulating the roof caving process, the periodic roof weighting intervals are calculated. Sensitivity analysis is then applied in order to determine the effect of changes in the mechanical properties of the rock mass, especially in the main roof and immediate roof. Results show that the applied algorithm in this study can effectively calculate the periodic roof weighting interval in the longwall mining method. Also, due to the flexible nature of numerical modeling, a reliable application of this approach can be envisaged in most mining conditions.
\end{abstract}

Keywords: Longwall Mining; Periodic Roof Weighting Interval; Finite Element Method; Phase2 Software

\section{Introduction}

The process of periodic loading in longwall mining is complex and significantly influences safety, stability, performance and the productivity of mining operations (Singh and Singh 2010). Periodic loading and the periodic roof weighting interval are related to geo-mechanical conditions of the surrounding rock mass, particularly to the immediate roof (Peng 2006). Roof caving mechanism and the rate of advance represent additional influences on the state of periodic loading.

The roof weighting interval increases due to a delay in caving (or un-caving) of the roof and a great deal of subsequent pressure on the power support system, which affects the mining operation (Peng 2008). Therefore, it is necessary to study the process of periodic loading in longwall mining, especially in a mechanization mining operation. Up until now, several studies have been carried out to determine the status of periodic loading, first roof weighting interval, periodic roof weighting interval and various equations have been derived (Peng 2006; Peng 2008; Jeremic 1985; Trueman et al. 2009). However, due to their analytical and experimental natures, these equations have some limits (Trueman et al. 2009). Generally in these equations, providing the initial assumptions is difficult in addition to the fact that their flexibility to different conditions is limited. Therefore, in this study, a new approach based on numerical modeling has been used to estimate the mechanism of periodic loading and calculate the roof weighting interval. Due to some difficulties — including structure of longwall panel, stress distribution and caving mechanism - the finite element method has been selected for numerical modeling (Oraee et al. 2009). The Phase 2 software is used for modeling, which is provided by Rocscience Inc. as a well-known finite element code (ROCSCIENCE 2011). In order to perform the modeling process using Phase2, the material properties and geometry of the problem are first defined. For this paper, the state of

\footnotetext{
${ }^{1}$ Department of Mining Engineering, South Tehran Branch, Islamic Azad University, Tehran, Iran, navid.hosseini@gmail.com

${ }^{2}$ Department of Mining Engineering, Tarbiat Modares University, Tehran, Iran

${ }^{3}$ Centre for Environmental Policy, Imperial College London, London, UK
} 
periodic loading in one of the longwall mining panels of Tabas coal mine in Iran (Hosseini 2010) has been simulated as a case study.

\section{Immediate roof}

The immediate roof is the lowest part of the roof that is caved while advancing the power supports. When modeling the roof weighting interval, the thickness of the immediate roof should be calculated. For this purpose, equations 1 to 3 are used (Peng 2006; Peng 2008).

$$
h_{i m}=\frac{H-d}{M-1}
$$

$d_{0} \geq d$

$d=c . H$

where, $h_{i m}$ is the thickness of the immediate roof, $H$ is the mining height, $d$ is the sagging of the lowest uncaved strata, $d_{0}$ is the maximum allowable sagging (without breaking) of the lowest un-caved strata, $c$ is the ratio of the actual sagging of the strata before caving to the mining height and $M$ is bulking factor of the immediate roof. The parameters $M$ and $c$ are dependent on the rock type and the mechanical properties of the immediate roof respectively. In the case of Tabas coal mine, they have been determined to be 1.25 and 0.50 respectively (Hosseini 2010). Furthermore, the coal seam thickness (mining height) has previously been determined to be $1.8 \mathrm{~m}$ (Hosseini 2010). Therefore, the thickness of the immediate roof is calculated as $3.6 \mathrm{~m}$.

\section{In-situ stress}

The state of in-situ stress can significantly influence the geo-mechanical behavior of the rock mass and can have major effects on the caving mechanism (Brady and Brown 2004). Equations 4 to 6 are used to calculate the state of in-situ stress (Sheorey 1997).

$$
\sigma_{v}=\gamma \cdot Z
$$

$k=0.25+7 E_{h}\left[0.001+\frac{1}{Z}\right]$

$$
\sigma_{h}=k \cdot \sigma_{v}
$$

where, $\sigma_{v}$ is the vertical in-situ stress, $\gamma$ is the average density of overburden, $Z$ is the depth below the ground surface, $k$ is the ratio of horizontal to vertical in-situ stress, $E_{h}$ is the average horizontal deformability modulus and $\sigma_{h}$ is the horizontal in-situ stress. The vertical and horizontal in-situ stresses in the Tabas coal mine have previously been calculated to be $12.50 \mathrm{MPa}$ and 4.71 MPa respectively (Hosseini 2010).

\section{Designation of rock mass properties in Phase2}

In order to perform numerical simulation, the mechanical properties of the immediate roof, floor and caving material (goaf area) must be defined. In the Tabas coal mine, roof and floor strata are a combination of sandstone, siltstone and mudstone (Hosseini 2010). The Hoek-Brown rock failure criterion has been selected based on the geo-mechanical behavior of rock mass for the modeling process in Phase2 (Hoek et al. 2002). 
Furthermore, the elastic properties of material and the type of material are defined as isotropic and plastic respectively (ROCSCIENCE 2011; Hosseini 2010). The average geo-mechanical properties of the roof, floor and coal are presented in table 1 .

Table 1: geomechanical properties of materials (Hosseini 2010)

\begin{tabular}{|c|c|c|}
\hline Parameters & Roof and floor & Coal \\
\hline$\sigma_{c i}(\mathrm{MPa})$ & 25.6 & 7 \\
\hline$G S I$ & 67 & 43 \\
\hline$m_{i}$ & 12 & 10 \\
\hline$\gamma\left(\mathrm{kg} / \mathrm{cm}^{3}\right)$ & 2730 & 1350 \\
\hline$E_{i}(\mathrm{GPa})$ & 2.83 & 0.26 \\
\hline$v$ & 0.31 & 0.29 \\
\hline$\sigma_{T i}(\mathrm{MPa})$ & 2.5 & 0.1 \\
\hline$\tau_{i}(\mathrm{MPa})$ & 17.66 & 5.5 \\
\hline
\end{tabular}

where, $\sigma_{c i}$ is the uniaxial compressive strength of intact rock, GSI is the geological strength index, $m_{i}$ is the intact rock parameter, $\gamma$ is the density, $E_{i}$ is the Young's modulus of intact rock, $v$ is the Poisson's ratio, $\sigma_{T i}$ is the tensile strength of intact rock and $\tau_{i}$ is the shear strength of intact rock.

The RocData software (ROCSCIENCE 2011) is used to estimate the rock mass properties of roof, floor and coal seam since the samples of intact rock are used in laboratory tests. RocData, which is also provided, by Rocscience Inc., determines the soil and rock mass strength parameters by analyzing laboratory or field triaxial/direct shear data. This program can fit the linear failure criterion (Mohr-Coulomb strength model) and three other non-linear failure criteria (the generalized Hoek-Brown, Barton-Bandis and Power Curve strength models) to test the data in order to estimate the full geo-mechanical parameters of rock mass (ROCSCIENCE 2011). An example of the calculated results of RocData is shown in figure 1.

Input parameters of RocData include uniaxial compressive strength of intact rock $\left(\sigma_{c i}\right)$, geological strength index ( $G S I$ ), intact rock parameter $\left(m_{i}\right)$ and disturbance factor $(D)$, all of which have been shown in Table 1 . 

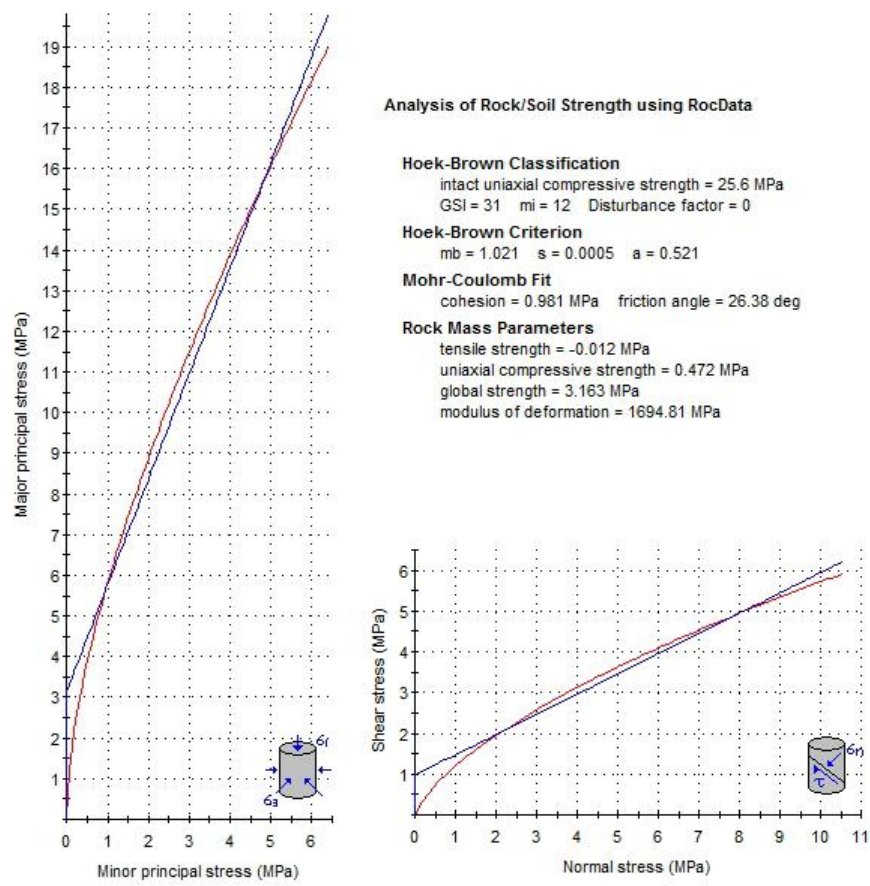

Figure 1, Output of RocData software

Due to rock quality and non-blasting extraction in Tabas coal mine, the disturbance factor is selected to be zero (Hoek et al. 1995). The results of RocData are shown in table 2.

Table 2: output of RocData software

\begin{tabular}{|c|c|c|}
\hline Parameters & Roof and floor & Coal \\
\hline$m_{b}$ & 1.021 & 0.554 \\
\hline$S$ & 0.0005 & 0.0001 \\
\hline$a$ & 0.521 & 0.547 \\
\hline$C(M P a)$ & 0.981 & 0.188 \\
\hline$\phi(\operatorname{deg})$ & 26.38 & 21.16 \\
\hline$\sigma_{T}(M P a)$ & -0.0117 & -0.0016 \\
\hline$\sigma_{c}(M P a)$ & 0.472 & 0.051 \\
\hline$\sigma_{c m}(M P a)$ & 3.163 & 0.549 \\
\hline$E_{m}(M P a)$ & 1694.81 & 444.17 \\
\hline
\end{tabular}

where $m_{b}, S$ and $a$ are the rock mass parameters; $C$ is the cohesion; $\phi$ is internal friction angle; $\sigma_{T}$ is tensile strength of rock mass; $\sigma_{c}$ is uniaxial compressive strength of rock mass; $\sigma_{c m}$ is global strength of rock mass and $E_{m}$ is deformation modulus of rock mass.

\section{Mechanical properties of caved materials (goaf)}

With the advancement of the face, the caved materials in the goaf area are gradually compressed; meaning that the mechanical properties of caved materials are a function of time. Based on the empirical studies conducted, 
the mechanical properties of goaf material can be calculated using equations 7 to 9 (Singh and Singh 2010; Jeremic 1985).

$$
\begin{aligned}
& \gamma=1600+800\left(1-e^{-1.25 t}\right) \\
& E=15+175\left(1-e^{-1.25 t}\right) \\
& v=0.05+0.2\left(1-e^{-1.25 t}\right)
\end{aligned}
$$

where $\gamma$ is the density, $E$ is the deformation modulus, $v$ is the Poisson's ratio and $t$ is the time. Based on this study and other mechanical properties (Hosseini 2010), the density, deformation modulus and Poisson's ratio of caved materials are calculated to be $1678 \mathrm{~kg} / \mathrm{cm}^{3}, 32.12 \mathrm{MPa}$ and 0.07 respectively.

\section{Numerical modeling and calculation of roof weighting interval}

In order to perform the numerical modeling, the finite element software, Phase2, has been used. The first stage of the model consists of the definition of the geometry of the roof model and situation, immediate roof, floor, coal seam and goaf, as well as the geo-mechanical properties of materials. Secondly, the geo-mechanical properties of the material in each part are assigned. In order to simulate the power support system, an equally distributed normal force is applied on the roof and floor. The advancement in each cutting cycle is defined in a separate stage. Overall, 20 stages have been defined within the model. In each stage, the distributed normal force (the equivalent force of power support system) advances with the face. Moreover, the part of immediate roof that yields is replaced with the caved material. Figure 2 shows the stage 1 of the created model in Phase2 and figure 3 shows the calculation of the first roof weighting interval.

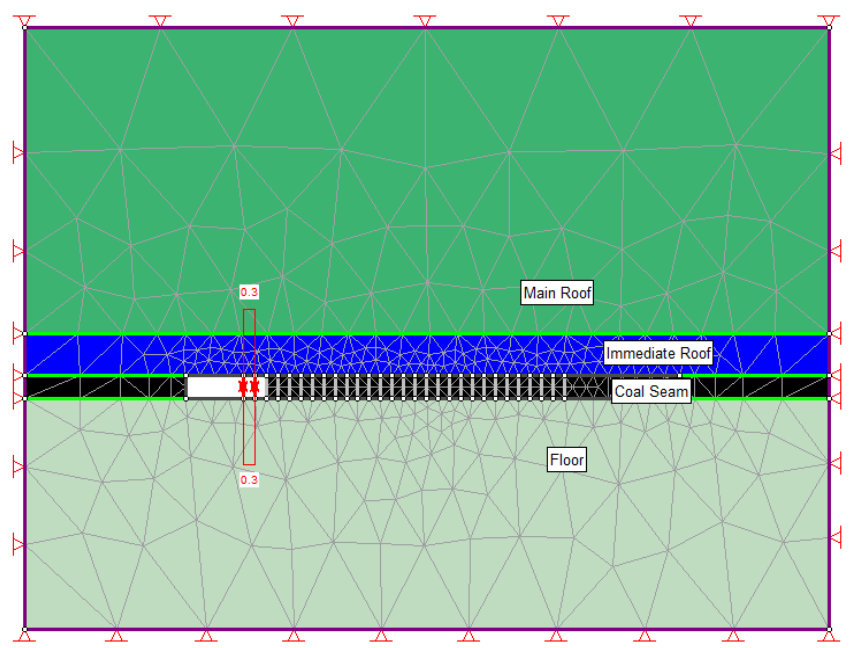

Figure 2, Created model in Phase2 - stage 1 


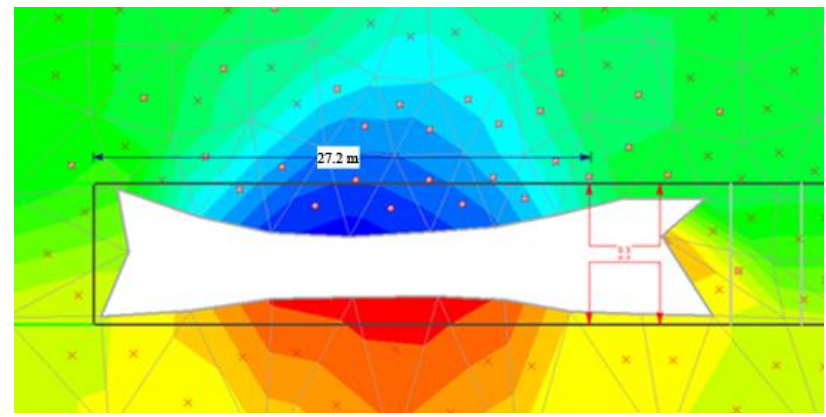

Figure 3, Calculation of first roof weighting interval

As it is evident form figures 3 and 4, with the advancement of the face and the power support system, the first caving zone is created in the immediate roof. In order to determine the first roof weighting interval, the yielded element of immediate roof has to be considered. Based on the results of numerical modeling, the first roof weighting interval is calculated as $27.2 \mathrm{~m}$. After the first caving, the yielded elements of immediate roof are replaced with caved materials (shown in figure 4). Afterwards, the face of the longwall is advanced gradually along with the power support that is applied in the model as a distributed normal force. When the unsupported length of roof reaches $12.1 \mathrm{~m}$, the immediate roof elements are yielded again. In other words, the roof is caved. Therefore, the periodic roof weighting interval is calculated to be $12.1 \mathrm{~m}$ (shown in figure 5).

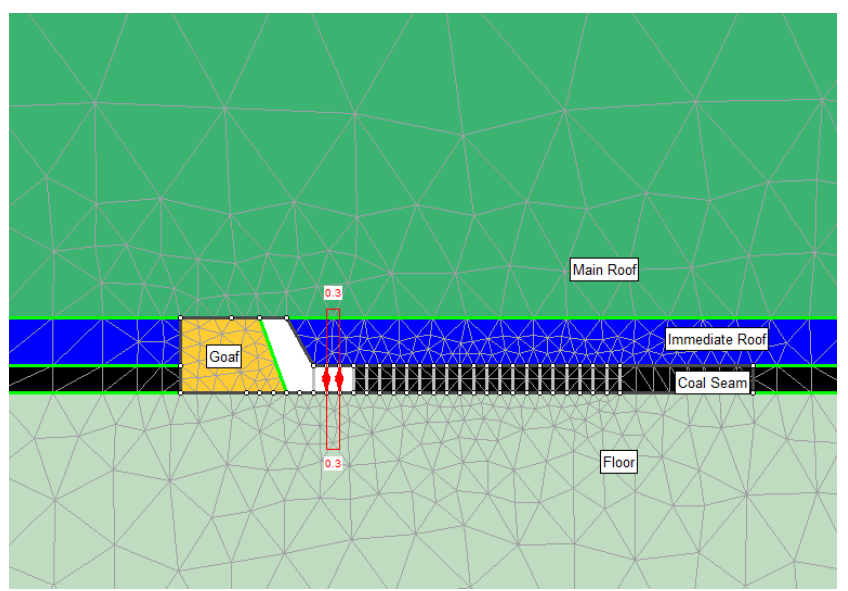

Figure 4, Numerical model after roof caving

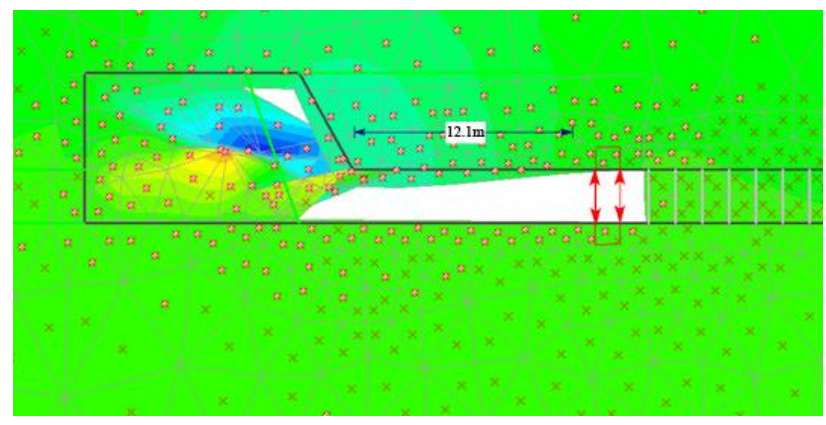

Figure 5, Calculation of the periodic roof weighting interval 


\section{Sensitivity analysis}

The geological strength index (GSI) (Hoek et al. 1995; Hoek and Brown 1997) is one of the important parameters that describes the geo-mechanical behavior of a given rock mass. This index is easy to estimate and is based on several equations. It is also related to other mechanical properties of rock, such as RMR, and Q (Edelbro 2003; Singh and Goel 1999). In this section, the state of the immediate roof is described based on the GSI. In order to determine the effect of changes in the mechanical properties of immediate roof on periodic roof weighting interval (PRWI), a sensitivity analysis has been conducted. For this purpose, the immediate roofs with different GSIs are defined in the numerical model and the PRWIs are calculated. The results can be seen in figure 6 .

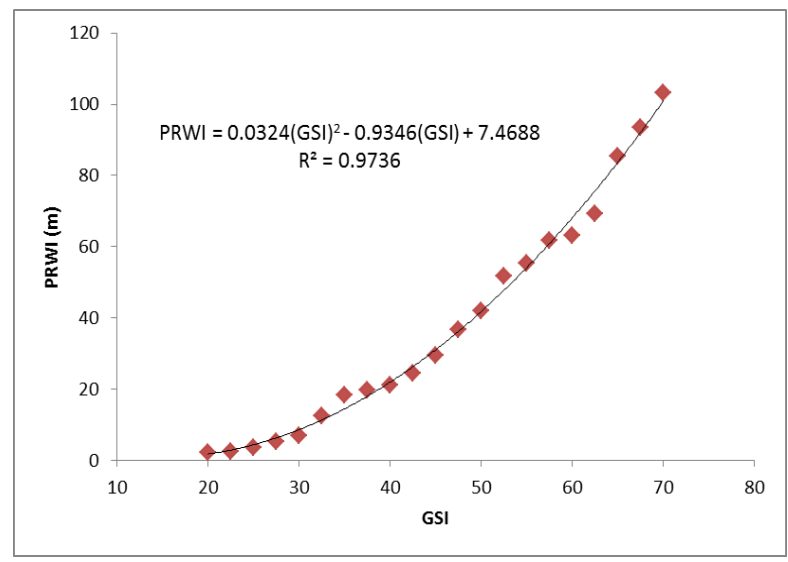

Figure 6, Periodic roof weighting interval vs. GSI

The PRWI increases as the GSI of the immediate roof is increased. This relationship can be defined based on equation 10.

$$
P R W I=0.0324(G S I)^{2}-0.9346(G S I)+7.4688
$$

\section{Conclusions}

In the design process of longwall mining and the selection of power support system, the periodic loading must be considered. Therefore, calculating the first and periodic roof weighting interval plays an important role in design process, safety, performance and the operation of the longwall mining method. Several methods are currently available that can be used in order to calculate the periodic loading and periodic roof weighting interval; however, due to some assumptions and other limitations, they are often difficult to use. The method presented in this study - a new approach based on numerical modeling — can be used to calculate the periodic loading and PRWI. Furthermore, this approach is simple and flexible since it is a numerical method. In addition, sensitivity analysis shows that the periodic loading is dependent on the geo-mechanical properties of the immediate roof. Therefore, PRWI is calculable based on the mechanical properties of the immediate roof, such as GSI. Generally, with the increase in quality of the immediate roof, the PRWI increases and subsequently the applied load on power support system is increased to the extent that it has the potential to threaten mining operations. 


\section{References}

Brady B.H.G. and Brown E.T., (2004), "Rock mechanics for underground mining", London: George Allen \& Unwin.

Edelbro C., (2003), "Rock mass strength: a review", Technical Reports, Luleå University of Technology, Department of Civil Engineering Division of Rock Mechanics.

Hoek E. and Brown E.T., (1997), "Practical estimates or rock mass strength.” International Journal of Rock Mechanics and Mining Sciences and Geomechanics Abstracts, 34(8) 1165-1186.

Hoek E., Carranza-Torres C. and Corkum B., (2002), "Hoek-Brown failure criterion-2002 Edition”, Rocscience Inc. <http://www.rocscience.com/hoek/references/H2002.pdf>; [accessed 10.20.11].

Hoek E., Kaiser P.K. and Bawden W.F., (1995), "Support of underground excavations in hard rock”, Rotterdam, Netherlands: A. A. Balkema.

Hosseini N., (2010), “The geo-mechanical study of panel II-Tabas Collieries.” Technical Report, Maadankavan Bisotun Co., Tehran, Iran.

Jeremic M. L., (1985), “Strata Mechanics in Coal Mining”, A.A. BALKEMA, Rotterdam, Netherlands.

Oraee K., Hosseini N. and Gholinejad M., (2009), "Estimation of Coal Pillar Strength by Finite Difference Model", Proceedings of the 2009 Coal Operators' Conference, Wollongong, Australia, 53-60.

Peng S.S., (2006), "Longwall Mining, $2^{\text {nd }}$ edition”, Society for Mining, Metallurgy, and Exploration, Inc. (SME).

Peng S.S., (2008), “Coal Mine Ground Control, $3^{\text {rd }}$ edition”, Society for Mining, Metallurgy, and Exploration, Inc. (SME).

ROCSCIENCE Inc., Phase2 Software, RocData Software (2011). Rocscience Inc. <http://www.rocscience.com>; [accessed 10.13.11].

Sheorey P.R., (1997), “Empirical rock failure criteria”, Rotterdam, Netherlands: A. A. Balkema.

Singh B. and Goel R.K., (1999), "Rock mass classification — a practical approach in civil engineering”, Elsevier, Netherlands.

Singh G.S.P. and Singh U.K., (2010), "Numerical Modeling Study of the Effect of Some Critical Parameters on Caving Behavior of Strata and Support Performance in a Longwall Working”, Rock Mechanics and Rock Engineering, 43 (4), 475-489.

Trueman R., Lyman G. and Cocker A., (2009), "Longwall roof control through a fundamental understanding of shield-strata interaction”, International Journal of Rock Mechanics and Mining Sciences, 46(2) 371-380. 